\title{
\begin{tabular}{l|l}
\hline T $D D$ & Jurnal Inovasi, Evaluasi, dan Pengembangan Pembelajaran \\
\hline
\end{tabular}
}

\section{Pengaruh Model Pembelajaran Kontekstual (CTL) Terhadap Hasil Belajar IPA Siswa Kelas IV Sekolah Dasar}

\author{
Budiman \\ Program studi Pendidikan Jasmani Kesehatan dan Rekreasi, STKIP Yapis Dompu \\ E-mail: budimanmsaid@gmail.com
}

Article History: Received: 2021-08-19 || Revised: 2021-08-19 || Published: 2021-08-20

Sejarah Artikel : Diterima: 2021-08-19 || Direvisi: 2021-08-19 || Dipublikasi: 2021-08-20

\begin{abstract}
The problem answered in this study is "whether the contextual learning model (CTL) affects students' science learning outcomes, the material makes life schemes of several types of living things in the surrounding environment and the slogan of its preservation efforts at SD Negeri 29 Dompu in the Science subject for the 2019 learning year / 2020 ". This type of research is a quasi-experimental research with a quantitative approach. This form uses two groups, one group is given treatment, while the other group is not given treatment. The group that was given treatment was the experimental class with the contextual learning model (CTL), and the group that was not given treatment was the control class with conventional learning. The focus of presentation in this research is (1) contextual learning model (CTL) in class IV B, (2) conventional methods in class IV A, (3) pre-test and post-test, (4) even semester, (5) animal life cycle. The data were analyzed using statistical methods, namely the t-test calculation can see the effect of the contextual learning model (CTL) by comparing the control class and the experimental class. The statement is indicated by the value of $t_{\text {count }}>t_{\text {table }}$ or $7,123>1,677$. Based on the results of this analysis, it can be stated that there is a significant effect of the contextual learning model (CTL) on the learning outcomes of science students in class IV B (experiment) and class IV A (control class) at SD Negeri 29 Dompu in the 2019/2020 learning year.
\end{abstract}

Keywords: Contextual Learning (CTL), Learning Outcomes, IPA

\begin{abstract}
Abstrak
Permasalahan yang dijawab dalam penelitian ini adalah apakah model pembelajaran kontekstual (CTL) berpengaruh terhadap hasil belajar IPA siswa, materi membuat skema kehidupan beberapa jenis makhluk hidup di lingkungan sekitarnya dan slogan upaya pelestariannya di SD Negeri 29 Dompu. pada mata pelajaran IPA tahun pelajaran 2019/2020 ". Jenis penelitian ini adalah penelitian eksperimen semu dengan pendekatan kuantitatif. Bentuk ini menggunakan dua kelompok, satu kelompok diberi perlakuan, sedangkan kelompok lainnya tidak diberi perlakuan. Kelompok yang diberi perlakuan adalah kelas eksperimen dengan model pembelajaran kontekstual (CTL), dan kelompok yang tidak diberi perlakuan adalah kelas kontrol dengan pembelajaran konvensional. Fokus penyajian dalam penelitian ini adalah (1) model pembelajaran kontekstual (CTL) di kelas IV B, (2) metode konvensional di kelas IV A, (3) pre-test dan post-test, (4) semester genap, (5)) siklus hidup hewan. Analisis data menggunakan metode statistik yaitu perhitungan uji-t dapat melihat pengaruh model pembelajaran kontekstual (CTL) dengan membandingkan kelas kontrol dan kelas eksperimen. Pernyataan tersebut ditunjukkan dengan nilai $t_{\text {hitung }}>t_{\text {tabel }}$ atau 7,123>1,677. Berdasarkan hasil analisis tersebut, dapat dinyatakan bahwa terdapat pengaruh yang signifikan model pembelajaran kontekstual (CTL) terhadap hasil belajar IPA siswa kelas IV B (eksperimen) dan kelas IV A (kelas kontrol) di SD. Negeri 29 Dompu pada tahun pembelajaran 2019/2020.
\end{abstract}

Kata kunci: Pembelajaran Kontekstual (CTL), Hasil Belajar, IPA

\section{PENDAHULUAN}

Pendidikan pada dasarnya merupakan salah satu upaya untuk memberikan pengetahuan, wawasan, keterampilan dan keahlian tertentu kepada individu-individu guna menggali dan mengembangkan bakat serta kepribadian, pendidikan memiliki peranan yang sangat penting guna meningkatkan sumber daya manusia yang ada karena melalui pendidikan dapat menciptakan generasi yang unggul dan kompentitif dalam menghadapi tantangan yang terjadi di masa 
mendatang.Pendidikan dapat diperoleh baik secara formal yaitu di sekolah-sekolah maupun informal yaitu di luar sekolah, contohnya di rumah.

Dalam upaya peningkatan mutu pendidikan khususnya dalam meningkatkan hasil pendidikan, satu diantaranya yang harus dikembangkan terletak pada proses belajar mengajar. Hal ini merupakan kegiatan yang paling pokok dalam proses pendidikan. Dengan demikian berhasil atau tidaknya pencapaian tujuan pendidikan dipengaruhi keberhasilan proses belajar mengajar, salah satu upaya untuk meningkatkan kualitas proses pembelajaran dapat dilakukan dengan memperbaiki model yang digunakan. Model pembelajaran yang pilih, hendaknya dapat memberikan hasil yang baik serta mampu meningkatkan aktivitas siswa. Siswa akan lebih tertarik untuk belajar jika guru mampu menggali pengetahuan yang telah dimiliki siswa, kemudian menghubungkan dengan pengetahuan yang baru. Apalagi jika guru mampu menghubungkan dengan situasi nyata siswa, maka siswa senantiasa lebih tertarik untuk belajar serta tidak membuat siswa jenuh.

Salah satu model pembelajaran yang dapat meningkatkan kreativitas siswa dalam proses pembelajaran adalah model pembelajaran kontekstual (Contextual Teaching and Learningatau CTL), Menurut Aqib (2016: 1) "Model pembelajaran kontekstual (CTL) merupakan konsep belajar yang membantu guru mengaitkan antara materi yang diajarkan dengan situasi dunia nyata siswa dan mendorong siswa untuk membuat penerapannya dalam kehidupan mereka sebagai anggota keluarga dan masyarakat", Jhonson (dalam Wulandari, 2018: 11) mengatakan bahwa "pembelajaran kontekstual adalah suatu sistem pembelajaran yang cocok dengan otak yang menghasilkan makna dengan menghubungkan muatan akademis dengan konteks dari kehidupan sehari-hari peserta didik. Jadi, pembelajaran kontekstual (CTL) adalah usaha untuk membuat peserta didik aktif dalam memompa kemampuan diri tanpa merugi dari segi manfaat, sebab peserta didik berusaha mempelajari konsep sekaligus menerapkan dan mengaitkannya dengan kehidupan nyata", Jadi peneliti menyimpulkan bahwa model pembelajaran kontekstual (CTL) adalah konsep belajar yang memudahkan guru dan siswa dalam memahami materi, pada pendekatan ini menghubungkan isi materi dengan dunia nyata siswa dalam memecahkan masalahmasalah yang bersifat simulatif ataupun nyata.

Penerapan model pembelajaran kontekstual (CTL) sebagaimana yang dikemukakan di atas, diharapkan dapat meningkatkan hasil belajar siswa, Menurut Rusman (dalam Handoyo, 2018: 47) bahwa "hasil belajar adalah sejumlah pengalaman yang diperoleh siswa yang mencakup ranah kognitif, afektif dan psikomotor, belajar tidak hanya penguasaan konsep teori mata pelajaran saja, tetapi juga penguasaan kebiasaan, persepsi, kesenangan, minat bakat, penyesuaian sosial, jenisjenis keterampilan, cita-cita, keinginan dan harapan". Menurut Dimyati dan Mudjiono (dalam Fu'ady, 2018: 21) "hasil belajar merupakan hasil dari suatu interaksi tindak belajar dan tindak mengajar, dari sisi guru, tindak mengajar diakhiri dengan proses evaluasi hasil belajar dari sisi siswa, hasil belajar merupakan berakhirnya penggal dan puncak proses belajar".Berdasarkan pendapat para ahli, penulis menyimpulkan bahwa hasil belajar adalah suatu hasil pembelajaran yang diperoleh siswa setelah melalui proses belajar dan diakhiri dengan evaluasi hasil belajar yang mencakup ranah kognitif, afektif dan psikomotorik siswa.

Berdasarkan hasil wawancara dengan guru (berinisial S) yang dilakukan oleh peneliti pada tanggal 21 Juni 2019 di SD Negeri 29 Dompu, diperoleh nilai rata-rata siswa kelas IV pada hasil ulangan semester mata pelajaran IPA hanya sebesar 65 dengan kriterial ketuntasan minimum (KKM) sebesar 75. Rendahnya hasil belajar tersebut disebabkan oleh guru hanya menggunakan metode ceramah dan pemberian tugas, siswa di dalam kelas hanya mencatat, mendengar dan melakukan kegiatan sesuai perintah guru, sehingga siswa merasa jenuh dan kurang fokus dalam pelajaran, Berdasarkan masalah di atas, penggunaan model pembelajaran sangat diperlukan untuk meningkatkan hasil belajar terutama hasi belajar IPA, oleh karena itu, guru hendaknya memilih sebuah model pembelajaran yang dapat menciptakan suasana belajar-mengajar yang kondusif agar mendorong siswa untuk aktif bertanya, aktif berpendapat, membangun gagasan dan melakukan kegiatan yang dapat memberikan pengalaman langsung sehingga belajar merupakan proses aktif siswa dalam membangun pengetahuannya sendiri, kondisi yang seperti inilah yang sangat diharapkan agar interaksi berjalan dengan baik demi pencapaian tujuan pembelajaran, Berdasarkan paparan diatas, peneliti tertarik untuk melakukan penelitian agar dapat mengetahui pengaruhnya terhadap hasil belajar siswa dengan judul "Pengaruh model pembelajaran kontekstual 
(CTL) terhadap hasil belajar IPA siswa kelas IV di SD Negeri 29 Dompu Tahun Pembelajaran 2019/2020".

\section{METODE PENELITIAN}

Penelitian yang dilakukan adalah penelitian eksperimen, yaitu penelitian yang digunakan untuk mencari pengaruh perlakuan (treatment) tertentu (Sugiyono, 2014), Jenis penelitian yang digunakan adalah eksperimen semu (quasy experiment) dengan pretest-posttestcontrol group design, eksperimen semu menggunakan seluruh subjek dalam kelompok belajar (intact group) untuk diberi perlakuan (tretment), bukan menggunakan subjek yang diambil secara acak (Tim Publitjaknov dalam Shopiatun, 2019: 38). Penelitian dengan Pretest-Post test Control Group Design dilakukan sebanyak dua kali yaitu sebelum eksperimen dengan Pre-test dan sesudah eksperimen dengan Post-test.

Tabel 1. Desain Penelitian pretest-posttest control group design

\begin{tabular}{cccc}
\hline Kelas & Pretest & Tindakan & Post-test \\
\hline Eksperimen & 01 & $\mathrm{X}$ & 02 \\
Kontrol & 03 & - & 04 \\
\hline
\end{tabular}

Keterangan:

01: Nilai Pre-test pada kelas eksperimen

02: Nilai Post-test pada kelas eksperimen

03: Nilai Pre-test pada kelas kontrol

04: Nilai Post-test pada kelas kontrol

Treatment Pembelajaran kontekstual $(C T L)$ diberikan untuk kelas eksperimen dan kelas kontrol tidak mendapat perlakuan atau menggunakan teknik pembelajaran yang konvensional. Setelah treatment dilakukan pada kelas eksperimen maka langkah selanjutnya melakukan Post-test, Posttest diberikan untuk mengukur perbedaan sebelum dan sesudah diberikan Treatment dengan memperhatikan kemampuan siswa berbeda-beda pada masing-masing kelas.

Jika nilai kelas eksperimen setelah diberikan treatment lebih signifikan atau berpengaruh dari kelas eksperimen sebelum diberikan treatment, maka teknik pembelajaran kontekstual (CTL) lebih efektif dibandingkan tanpa penggunaan pembelajaran kontekstual (CTL), begitu juga sebaliknya jika nilai kelas kontrol setelah diberikan treatment secara signifikan lebih tinggi sebelum diberikan treatment maka pembelajaran tanpa pembelajaran kontekstual (CTL) lebih efektif dari pada menggunakan teknik pembelajaran kontekstual $(C T L)$.

\section{HASIL DAN PEMBAHASAN}

\section{A. Hasil Penelitian}

Penelitian ini adalah penelitian Quasi Eksperimen (eksperimen semu) dengan menggunakan pendekatan kuantitatif yang dilaksanakan pada tangga 7 Januari 2020 sampai 19 Januari 2020 di SD Negeri 29 Dompu tahun pembelajaran 2019/2020 pada siswa yaitu kelas IV-A sebagai kelas kontrol dan kelas IV-B sebagai kelas eksperimen, adapun data yang diperoleh dalam penelitian ini berupa data tentang hasil belajar siswa.

\section{Uji Normalitas}

Data pada uji normalitas ini diperoleh dari hasil pre-test dan post-test, baik dikelas eksperimen maupun di kelas kontrol. Uji normalitas diujikan pada masing-masing variabel penelitian yaitu pre-test dan post-test kelas eksperimen maupun kelas kontrol, data dikatakan berdistribusi normal apabila nilai taraf signifikansi hitung lebih besar dari nilai taraf signifikansi $a=5 \%$ dengan perhitungan menggunakan chi kuadrat.

Tabel 2. Perhitungan Uji Normalitas Nilai Post-test Kelas Eksperimen

\begin{tabular}{cccccc}
\hline Interval & Fo & fh & (fo-fh) & (fo-fh) ${ }^{2}$ & $\begin{array}{c}\text { (fo-fh) } \\
\text { fh }\end{array}$ \\
\hline $60-65$ & 2 & 0.675 & 1.325 & 1.756 & 2.601 \\
\hline
\end{tabular}




\begin{tabular}{cccccc}
\hline $66-71$ & 2 & 3.335 & -1.335 & 1.782 & 0.534 \\
\hline $72-77$ & 8 & 8.49 & -0.490 & 0.240 & 0.028 \\
\hline $78-83$ & 6 & 8.490 & -2.490 & 6.200 & 0.730 \\
\hline $84-89$ & 5 & 3.335 & 1.665 & 2.772 & 0.831 \\
\hline $90-95$ & 2 & 0.675 & 1.325 & 1.756 & 2.601 \\
\hline & 25 & 25 & 0 & 0 & 7.326 \\
\hline
\end{tabular}

Harga fh $=2,7 \% \times 25=0,675 ; 13,34 \% \times 25=3,335 ; 33,96 \% \times 25=8,49 ; 33,96 \% \times 25=8,49$; $13,34 \%$ x $25=3,335 ; 2,7 \%$ x $25=0,675$

Berdasarkan perhitungan ditemukan harga Chi kuadrat $=7.326$ harga tersebut selanjutnya dibandingkan dengan chi kuadrat tabel, dengan dk (derajat kebebasan) 6 - 1=5. Bila dk 5 dan taraf kesalahan 5\%, maka harga Chi kuadrat tabel $=11,070$ karena harga Chi kuadrat hitung lebih kecil dari harga Chi kuadrat tabel $(7.326<11,070)$, maka data variabel pre-test kelas kontrol tersebut berdistribusi normal.

Tabel 3. Perhitungan Uji Normalitas Nilai Post-test Kelas Kontrol

\begin{tabular}{cccccc}
\hline Interval & fo & fh & (fo-fh) & (fo-fh) & (fo-fh) \\
& & & & & fh \\
\hline $50-55$ & 4 & 3.335 & 0.665 & 0.442 & 0.133 \\
\hline $56-61$ & 4 & 3.335 & 0.665 & 0.442 & 0.133 \\
\hline $62-67$ & 7 & 8.490 & -1.490 & 2.220 & 0.261 \\
\hline $68-73$ & 6 & 8.490 & -2.490 & 6.200 & 0.730 \\
\hline $74-79$ & 2 & 0.675 & 1.325 & 1.756 & 2.601 \\
\hline $80-85$ & 2 & 0.675 & 1.325 & 1.756 & 2.601 \\
\hline & 25 & 25 & 0 & 12.816 & 6.459 \\
\hline
\end{tabular}

Harga fh $=2,7 \%$ × $25=0,675 ; 13,34 \% \times 25=3,335 ; 33,96 \% \times 25=8,49 ; 33,96 \% \times 25=8,49$; $13,34 \%$ × $25=3,335 ; 2,7 \%$ × $25=0,675$

Berdasarkan perhitungan ditemukan harga Chi kuadrat $=6.459$ harga tersebut selanjutnya dibandingkan dengan chi kuadrat tabel, dengan dk (derajat kebebasan) 6 - 1=5. Bila dk 5 dan taraf kesalahan 5\%, maka harga Chi kuadrat tabel $=11,070$ karena harga Chi kuadrat hitung lebih kecil dari harga Chi kuadrat tabel $(6.459<11,070)$, maka data variabel pre-test kelas kontrol tersebut berdistribusi normal.

Tabel 4. Rangkuman Uji Normalitas Data Awal

\begin{tabular}{cccc}
\hline Variabel & $\mathbf{X}^{2}$ hitung & $\mathbf{X}^{2}$ tabel & Kriteria \\
\hline Pre-test eksperimen & 6.930 & 11,070 & Normal \\
\hline Post-test eksperimen & 7.326 & 11,070 & Normal \\
\hline Pre-test kontrol & 6.127 & 11,070 & Normal \\
\hline Post-test kontrol & 6.459 & 11,070 & Normal \\
\hline
\end{tabular}

Hasil ujian normalitas variabel penelitian dapat diketahui bahwa semua variabel pre-test dan post-test kelas eksperimen maupun Pre-test dan Post-test kelas kontrol dengan nilai taraf signifikansin $\mathrm{a}=5 \% \mathrm{X} 2$ hitung $<\mathrm{X} 2$ tabel sehingga dapat disimpulkan bahwa semua variabel Pretest dan Post-test kelas eksperimen maupun pre-test dan post-test kelas kontrol berdistribusi normal.

2. Uji Homogenitas

Uji homogenitas dimaksudkan untuk mengetahui apakah sampel yang diambil dari populasi berasal dari variansi yang sama dan tidak menunjukkan perbedaan yang signifikan satu sama 
lain. Tes statistik yang digunakan adalah Uji F, yaitu dengan membandingkan variansi terbesar dan variansi terkecil. Syarat agar variansi bersifat homogen apabila $F_{\text {hitung }}$ lebih kecil dari $F_{\text {tabel }}$ pada taraf signifikansi $a=5 \%$. Berarti data kedua kelompok tersebut homogen.

\section{Menghitung Uji F}

Setelah nilai $\left(\mathrm{S}^{2}\right)$ diperoleh dari tabel-tabel perhitungan varian pre-test dan post-test kedua kelas, maka selanjutnya akan diuji varian menggunakan uji $\mathrm{F}$ dalam tabel uji homogenitas.

1) Menghitung Nilai F Pre-test Kelas Eksperimen dan Kelas Kontrol.

$$
\begin{aligned}
& F=\frac{\text { Varian terbesay }}{\text { Varian terkecil }} \\
& F=\frac{91,86}{71,76} \\
& F=1.13
\end{aligned}
$$

Diperoleh harga $F_{\text {hitung }}=1.13$ maka harga $F_{\text {hitung }}$ tersebut selanjutnya dibandingkan dengan $F_{\text {tabel }}$ dengan dk pembilang $(25-1=24)$ dan dk penyebut $(25-1=24)$. Berdasarkan dk tersebut dan untuk kesalahan 5\%, maka harga $F_{\text {tabel }}=1,98$, dalam hal ini berlaku ketentuan bahwa, bila $F_{\text {hitung }}$ lebih besar dari pada $F_{\text {tabel, }}$ maka varian tidak homogen. Ternyata harga $F_{\text {hitung }}$ lebih kecil dari pada $F_{\text {tabel }}(1.13<1,98)$. Dengan demikian dapat dinyatakan bahwa varian kedua kelas pre-test tersebut adalah homogen.

2) Menghitung Nilai F Post-test Kelas Eksperimen Dan Kelas Kontrol

$$
\begin{aligned}
& F=\frac{\text { Varian terbesar }}{\text { Varian terkecil }} \\
& F=\frac{86,55}{7_{2} 04} \\
& F=1.12
\end{aligned}
$$

Diperoleh harga $\mathrm{F}_{\text {hitung }}=1.12$ maka harga $\mathrm{F}_{\text {hitung }}$ tersebut selanjutnya dibandingkan dengan $\mathrm{F}_{\text {tabel }}$ dengan dk pembilang $(25-1=24)$ dan dk penyebut $(25-1=24)$. Berdasarkan $\mathrm{dk}$ tersebut dan untuk kesalahan $5 \%$, maka harga $F_{\text {tabel }}=1,98$, dalam hal ini berlaku ketentuan bahwa, bila $F_{\text {hitung }}$ lebih besar dari pada $F_{\text {tabel, maka varian tidak }}$ homogen.Ternyata harga $F_{\text {hitung }}$ lebih kecil dari pada $F_{\text {tabel }}(1.12<1.98)$, dengan demikian dapat dinyatakan bahwa varian kedua kelas Post-test tersebut adalah homogen.

Tabel 5. Rangkuman Uji Homogenitas

\begin{tabular}{cccc}
\hline Kelompok & $\mathbf{F}_{\text {hitung }}$ & $\mathbf{F}_{\text {tabel }}$ & Keterangan \\
\hline Pre-test & 1.13 & 1,98 & $\mathrm{~F}_{\mathrm{h}}<\mathrm{F}_{\mathrm{t}}=$ Homogen \\
\hline Post-test & 1.12 & 1,98 & $\mathrm{~F}_{\mathrm{h}}<\mathrm{F}_{\mathrm{t}}=$ Homogen \\
\hline
\end{tabular}

Dari data di atas, menjelaskan bahwa untuk data Pre-test dan Post-test pada kelompok eksperimen maupun kelompok kontrol dapat diketahui nilai $F_{\text {hitung }}\left(F_{h}\right)$ lebih kecil dari $\mathrm{F}_{\text {tabel }}\left(\mathrm{F}_{\mathrm{t}}\right)$ dan nilai signifikansi lebih besar dari 5\% $(\mathrm{P}>0,05)$, yang berarti bahwa data Pretest dan Post-test kedua kelompok tersebut homogen, sehingga memenuhi syarat untuk dilakukan uji-t.

3. Uji Hipotesis

Untuk menguji hasil Uji-T, jika statistik $t_{\text {hitung }}$ diperoleh lebih besar dari $t_{\text {tabel }}$ maka hipotesis diterima, Makna Hasil Uji-T Hipotesis: Selain menggambarkan persamaan homogenitas dan normalitas data variabel, output ini juga menampilkan uji signifikansi dengan uji-t menggunakn rumus Polled Varians yaitu untuk mengetahui ada pengaruh yang nyata (signifikan) variabel (X) terhadap variabel (Y), sedangkan Hipotesis, Hipotesis statistik dalam penelitian ini diuji dengan menggunakan uji-t, dengan taraf signifikansi $a=5 \%$. Perhitungan uji-t tersebut diselesaikan dengan secara manual.Kriteria hipotesis diterima apabila $t_{\text {hitung }}$ lebih besar daripada $t_{\text {tabel }}$ pada taraf signifikansi 5\% maka Hipotesis diterima, Selanjutnya dilakukan Uji statistik dengan 
menggunakan rumus polled varians. Berdasarkan ketentuan bahwa $\mathrm{n}_{1}=\mathrm{n}_{2}$ dan varians homogen maka dapat digunakan rumus t-test dengan Polled Varians, (Sugiyono 2011: 197) dengan menggunakan rumus dan hasil perhitungan sebagai berikut:

$$
\begin{aligned}
& =\frac{\bar{x}_{1}-\bar{x}_{2}}{\sqrt{\frac{\left(n_{1}-1\right) s_{1}^{2}+\left(n_{1}-1\right) s_{2}^{2}}{n_{1}+n_{2}-2}\left(\frac{1}{n_{1}}+\frac{1}{n_{2}}\right)}} \\
& t=\frac{78,34-65,46}{\sqrt{\frac{(25-1) 86,55+(25-1) 77_{0}, 04}{25+25-2}\left(\frac{1}{25}+\frac{1}{25}\right)}} \\
& t=\frac{12,88}{\sqrt{\frac{(24) 86,55+(24) 77,04}{25+25-2}\left(\frac{1}{25}+\frac{1}{25}\right)}} \\
& t=\frac{12,88}{\sqrt{\frac{2.077,2+1.848,96}{48}\left(\frac{1}{25}+\frac{1}{25}\right)}} \\
& t=\frac{12,88}{\sqrt{\frac{2,926,16}{48}(0,04)}} \\
& t=\frac{12,88}{\sqrt{81,795(0,04)}} \\
& t=\frac{12,88}{\sqrt{3,2718}} \\
& t=\frac{12,88}{1,808} \\
& t=7,123
\end{aligned}
$$

Selanjutnya nilai $t_{\text {hitung }}$ dibandingkan dengan nilai $t_{\text {tabel }}$ dengan $\mathrm{dk}=\mathrm{n} 1+\mathrm{n} 2-2=25+25-2=48$ dan taraf signifikan 0,05 atau 5\%, maka $t_{\text {tabel }}=1,677$ (uji dua pihak dengan interpolansi), dalam hal ini berlaku ketentuan bahwa, bila $t_{\text {hitung }}$ lebih besar dari atau sama dengan $t_{\text {tabel, }}$ maka Hipotesis diterima. Ternyata $t_{\text {hitung }}$ lebih besar dari pada $t_{\text {tabel }}(7,123>1,677)$ dengan taraf signifikansi $a=$ 5\% maka Hipotesis diterima.

Simpulannya teknik pembelajaran mnemonik berpengaruh terhadap hasil belajar.

Tabel 6. Hasil Uji-tPost-test Hasil belajar

\begin{tabular}{ccccc}
\hline Kelas & $\mathbf{T}_{\text {hitung }}$ & $\mathbf{T}_{\text {tabel }}$ & $\begin{array}{l}\text { Taraf } \\
\text { Signifikansi } \\
\mathbf{5 \%}\end{array}$ & Keterangan \\
\hline Eksperime & 7,123 & 1,677 & 0,05 & $\begin{array}{l}\mathbf{t}_{\text {hitung }}>\mathrm{t}_{\text {tabel }} \\
\text { (signifikan) }\end{array}$ \\
\hline
\end{tabular}

Berdasarkan hasil analisis tabel di atas dapat dilihat perhitungan $t_{\text {hitung hasil belajar (Post-test) }}$ sebesar 7, 123 Kemudian nilai $t_{\text {hitung }}$ dikonsultasikan dengan nilai $t_{\text {tabel }}$ pada taraf signifikansi $a=$ 0,05 , diporeleh $t_{\text {tabel }} 1,677$. Hal ini menunjukkan bahwa nilai $t_{\text {hitung }}$ lebih besar daripada $t_{\text {tabel }}$ ( $t_{\text {hitung }} 7,123>t_{\text {tabel }} 1,670$ ), maka hipotesis diterima, Artinya terdapat pengaruh yang signifikan teknik pembelajaran aktif terhadap prestasi belajar. 


\section{B. Pembahasan}

a) Pembelajaran Kontekstual (CTL)

Pembelajaran kontekstual (CTL) adalah pembelajaran yang digunakan dalam penelitian ini. Pembelajaran kontekstual (CTL) memiliki peran yang sangat penting dalam meningkatkan hasil belajar siswa karena pembelajaran ini dapat memperlancar pemahaman dan memperkuat daya ingat siswa, sampel yang digunakan dalam penelitian ini adalah seluruh siswa IV yaitu kelas IV A sebagai kelas kontrol dan IV B sebagai kelas eksperimen yang diberikan perlakuan dengan model pembelajaran kontekstual (CTL), pada kelas kotrol maupun kelas eksperimen akan diberikan tes awal (pre test) dan tes akhir (post test). Setelah kedua kelas tersebut diberikan tes awal (Post test), siswa melakukan proses pembelajaran sesuai dengan yang direncanakan. Pada kelas eksperimen siswa akan diberikan masalah terkait dengan tema yang dipelajari dan melakukan Tanya jawab serta tukar pikiran dengan cara berdiskusi. Kemudian menyampaikan pendapat dan mengembangkan potensi yang dimiliki di depan kelas dan diberikan tes akhir (Post test) sebagai langkah terakhirnya.

C. Hasil Belajar

Berdasarkan dari uji hipotesis, setelah diberikan perlakuan dengan model pembelajaran kontekstual $(C T L)$, diperoleh nilai thitung $=7,123$ dengan ttabel untuk kesalahan 5\% uji dua pihak $\mathrm{dk}=\mathrm{n} 1+\mathrm{n} 2-2=48$ maka diperoleh ttabel $=1,677$, ternyata nilai $t_{\text {hitung }} 7,123>1,677$ $t_{\text {tabel. }}$ Sehingga Ho ditolak dan Ha diterima, dapat disimpulkan ada pengaruh model pembelajaran kontekstual (CTL) terhadap hasil belajar IPA siswa kelas IV SD Negeri 29 Dompu tahun pembelajaran 2019/2020, Hasil tes awal (Pre-test) menunjukkan nilai rata-rata kelas eksperimen 47,66 dan nilai rata-rata kelas kontrol yaitu 49,96, sedangkan dari tes akhir (posttest) yang dilakukan setelah diberikan kegiatan pembelajaran dengan model pembelajaran kontekstual (CTL) untuk kelas eksperimen dan tanpa model pembelajaran kontekstual (CTL) untuk kelas kontrol, diperoleh nilai rata-rata pada kelas eksperimen meningkat menjadi 78,32 dan nilai rata,rata kelas kontrol menjadi 65,44, dari hasil Post-test tersebut terlihat bahwa nilai rata-rata kelas eksperimen lebih tinggi daripada kelas kontrol.Ini menunjukkan bahwa model pembelajaran kontekstuan (CTL) lebih baik jika dibandingkan dengan siswa yang diajarkan tanpa model pembelajaran kontekstual (CTL).

D. Pengaruh Model Pembelajran Kontekstual (CTL) Terhadap Hasil Belajar

Berdasarkan hasil penelitian hipotesis dapat diketahui bahwa ada pengaruh yang signifikan model pembelajaran kontekstual (CTL) terhadap hasil belajar siswa kelas IV SD Negeri 29 Dompu yang diajarkan dengan menggunakan pembelajaran kontekstual (CTL) pada proses belajarnya. Hal ini dapat dilihat dari uji-t yaitu $t_{\text {hitung }}$ lebih besar dati $t_{\text {table }}$ dengan taraf signifikan 5\%, peningkatan hasil belajar tersebut dapat dilihat dari nilai rata-rata post test pada kelas eksperimen dan kelas kontrol. Akan tetapi, peningkatan hasil belajar tersebut yang paling menonjol ditunjukkan oleh kelas eksperimen dengan rata-rata sebesar 78, 34. Selain itu juga diketahui dari masing-masing variable dalam penelitian ini berdistribusi normal, hal ini dibuktikan dengan uji normalitas, kemudian dilakukan uji homogenitas dengan taraf signifikan $5 \%$ atau a $=0,05$.

Berdasarkan nilai perhitungan selanjutnya nilai $t$ hitung dibandingkan dengan nila $t$ tabel dengan $\mathrm{dk}=\mathrm{n} 1+\mathrm{n} 2-2=25+25-2=48$ dan taraf signifikan 0,05 atau $5 \%$ maka $\mathrm{t}$ tabel $=1,677$. Dalam hal ini berlaku ketentuan bahwa, bila $t$ hitung lebih besar dari t table, mak hipotesis yang diajukan diterima, Ternyata $t_{\text {hitung }}$ lebih besar dari pada $t_{\text {tabel }}(7,123>1,677)$ dengan taraf signifikan $\mathrm{a}=5 \%$ maka hipotesis diterima. Simpulannya model pembelajaran kontekstual $(C T L)$ berpengaruh terhadap hasil belajar siswa.

\section{SIMPULAN DAN SARAN}

\section{A. Simpulan}

Berdasarkan penelitian yang telah dilakukan pengaruh model pembelajaran kontekstual (CTL) terhadap hasil belajar IPA siswa kelas IV SD Negeri 29 Dompu tahun pembelajaran 2019/2020. Setelah dianalisis dapat diambil kesimpulan sebagai berikut: (1) Terdapat pengaruh hasil belajar siswa yang signifikanpada penggunaan model pembelajaran kontekstual (CTL) terhadap hasil belajar daripada dengan menggunakan metode konvensional, (2) Dengan hasil 
uji-t diperoleh nilai thitung sebesar 7,123 dan nilai ttabel sebesar 1,677 dengan angka signifikansi 0,05 yang berarti teknik pembelajaran aktif berpengaruh terhadap hasil belajar sehingga hipotesis diterima.

\section{B. Saran}

Berdasrkan hasil penelitian dan pembahasan, saran yang diperlukan pada penelitian ini sebagi berikut: (1) Guru memahami setiap langkah-langkah model pembelajaran kontekstual (CTL) sehingga guru dapat mengajarkan kepada siswa dengan baik, (2) Aturan yang diterapkan pada kegiatan pembelajaran kontekstual harus disampaikan secara jelas dan bersifat tegas bagi seluruh siswa, (3)Tahapan kegiatan model pembelajaran kontekstual dijelaskan secara rinci kepada siswa, sehingga siswa dapat mengikuti setiap tahapan dengan mudah.

\section{DAFTAR RUJUKAN}

Arikunto, Suharsimi. 2010. Prosedur Penelitian Suatu Pendekatan Praktik. Edisi Revisi 2010. Jakarta: Rineka Cipta

Aqib, Z. 2016. Model-Model Pembelajaran dan Strategi PembelajaranKontekstual ( Inovatif). Bandung: Yrama Widya.

Fu'ady, Alwan Mohamad. 2018. Pengaruh Motivasi Terhadap Hasil Belajar Siswa Pada Pembelajaran Tematik Kelas IV SD Negeri 33 Gedong Tataan Pesawaran Lampung, (Online), (http://digilib.unila.ac.id/32334/2/skripsi\%20tanpa\%20bab\%20pembahasan.pdf), diakses 20 juli 2019)

Hamalik, Oemar. 2014. Kurikulum dan Pembelajaran. Jakarta: Bumi Aksara

Handoyo, Ari. 2018. Hubungan Kreativitas Dengan Hasil Belajar Siswa Kelas V Mata Pelajaran Bahasa Indonesia Di Mi Ma'had Islamy Palembang. Jurnal Ilmiah PGMI (Online), Volume 4, No. 1, (http://journal.student.uny.ac.id/ojs/index.php/pgsd/article/download/135, diakses 25 juni 2019)

Hijriatul. 2018. Pengaruh Penguasaan Materi Mengajar Guru Terhadap Hasil Belajar Siswa Sd Negeri 29 Dompu. Skipsi Tidak diterbitkan. Dompu: STKIP Yapis Dompu

Nurlaila. 2018. Pengaruh Sarana Prasarana Terhadap Prestasi Belejar Siswa Kelas V di SD Negeri 29 Dompu. Skripsi Tidak diterbitkan. Dompu: STKIP Yapis Dompu.

Prabowo, Imam H. 2018. Pengaruh Pendekatan Kontekstual Terhadap Hasil Belajar IPA Siswa $\begin{array}{llllllll}\text { Kelas } & V & S D & N & 6 & \text { Metro } & \text { Utara, } & \text { (Online), }\end{array}$ (http://digilib.unila.ac.id/29012/2/skripsi\%20Tanpa\%20Bab\%PEMBAHASAN, diakses 18 juli 2019)

Rusman. 2016. Model-Model Pembelajaran Mengembangkan Profesionalisme Guru. Edisi Revisi II. Jakarta: Raja Grafindo Prsada.

Subaidah, Ida. 2018. Upaya Peningkatan Aktivitas Dan Hasil Belajar PKn Melalui Model Pembelajaran Tipe Stad Pada Kelas IV SDN 4 Sawah Lama Kecamatan Tanjung Karang Timur Kota Bandar Lampung Tahun Pelajaran 2017/2018 (Online), (http://digilib.unila.ac.id/30327/2/SKRIPSI\%20TANPA\%20BAB\%20PEMBAHASAN.pdf, diakses 30 juni 2019)

Sugiyono.2014.Metodelogi Penelitian Pendidikan. Bandung: Alfabeta

Wulandari, Putri. 2018. Pengaruh Model Pembelajaran Contextual Teaching And Learning Terhadap Hasil Belajar Peserta Didik Mata Pelajaran Akidah Akhlak Kelas V Di Min 8 (Online), (http://repository.radenintan.ac.id/4601/1/skripsi\%20putri.pdf, diakses 22 juni 2019) 
